\title{
Abscess formation after transobturator sling placement: a case report
}

\author{
Joao Colaco • Vitor Goncalves • Catarina Pinto • \\ Clara Castro • Agueda Vieira $\cdot$ Helio Retto
}

Received: 19 July 2006 / Accepted: 9 January 2007 / Published online: 16 February 2007

(C) Springer-Verlag 2007

\begin{abstract}
New techniques of sling placement may be associated with infectious complications. Slings through the obturator foramen and thigh can lead to a significant abscess formation within the thigh adductor muscles. A large thigh abscess associated with a transobturator sling was diagnosed and treated. The authors report the evaluation and treatment of a unique infectious complication of transobturator slings.
\end{abstract}

Keywords Transobturator tape complications · ObTape ·

Stress urinary incontinence $\cdot$ Abscess formation

\section{Introduction}

The transobturator tape (TOT) procedure was described in 2001 as a new minimally invasive procedure for urinary stress incontinence, with the proposed advantage over the retropubic procedure [1], with minor vascular and bladder complications and a shorter intra-operative period. The transobturator monofilament polypropylene sling (Mentor ObTape) procedure uses an implantable transobturator suburethral support tape for the surgical treatment of all types of stress urinary incontinence. The device is made of heat-soldered monofilament strands of nonwoven polypro-

J. Colaco $(\bowtie) \cdot$ V. Goncalves $\cdot$ C. Pinto $\cdot$ A. Vieira $\cdot$ H. Retto

Urogynecology and Reconstructive Pelvic Surgery Unit,

Department of Obstetric and Gynecology,

Hospital Garcia de Orta,

2800 Almada, Portugal

e-mail: reiscolaco@netcabo.pt

C. Castro

Department of General Surgery, Hospital Garcia de Orta,

Almada, Portugal pylene fiber with pore size formed by the interlacing of the monofilaments being approximately $50 \mu \mathrm{m}$ and elasticity of $5 \%$ [2]. A great debate is held about the placement of macroporous mesh and its potential for infectious complications. We report a sole infectious complication for the transobturator sling. To the best of our knowledge, there is only one other case with this kind of complication, a large thigh abscess following the placement of a synthetic transobturator, described by Goldman [3].

\section{Case report}

A 48-year-old patient with a five year history of stress urinary incontinence was observed 2 years ago in our unit for urethral hypermobility. The result of urodynamics study supports the clinical findings of stress urinary incontinence. The patient was submitted to a transobturator monofilament polypropylene sling procedure (with the Mentor ObTape). There were no complications reported and the patient turned continent soon after. Five months after surgery the patient presented urinary incontinence, vaginal mesh extrusion and infection. A conservative treatment was implemented by removing the exposed mesh through vaginal route, closing the vaginal mucosa. Oral antibiotic therapy with $500 \mathrm{mg}$ of ofloxaciline for 7 days was administered.

Total removal of the mesh was decided upon because the patient had repeated episodes of vaginal infection and extrusion of small portions of the remaining mesh. This was performed through vaginal route 14 months after initial surgery for all attainable fragments.

Four months after mesh removal the patient complained of high fever, malaise, purulent vaginal discharge and higher engorgement in the left thigh extending to its inferior 


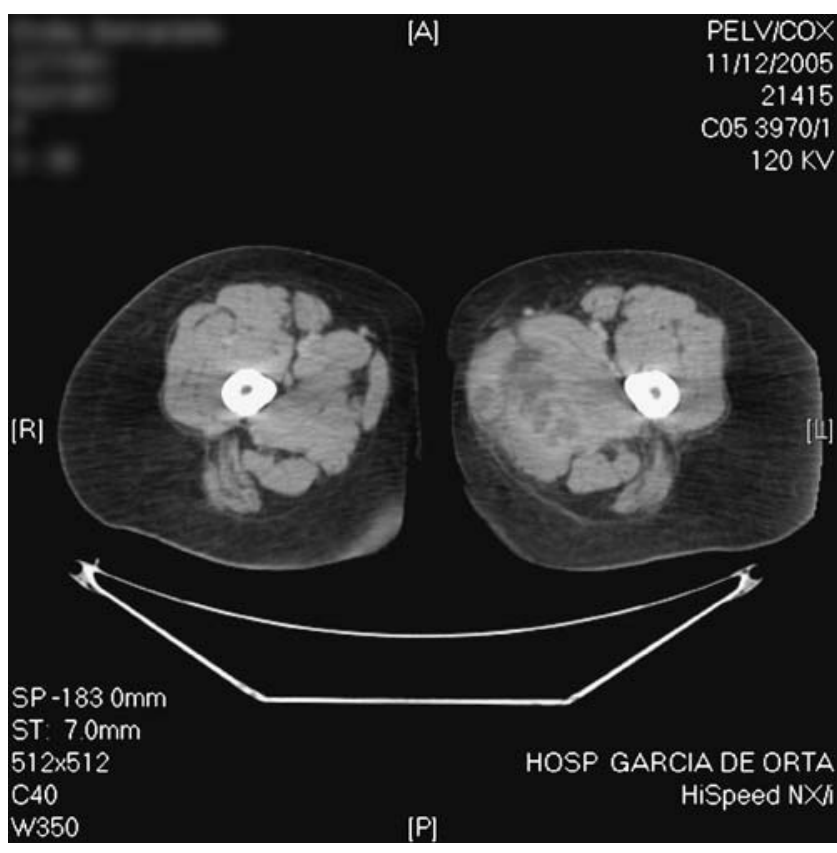

Fig. 1 Abscess at level of obturator region

portion associated with difficult mobilization and tenderness. A computerized scan revealed abscess collections at the level of the external obturator and left adductor muscles (Fig. 1). A surgical drainage was performed under general anaesthesia and the inner-thigh was incised which demonstrated normal fat and fascia appearance. Further dissection demonstrated abscess cavities within the gracilis and adductor magnus muscles. The infection tracked up to the level of the obturator externus and distally half way to the knee. Drains and packing were left in place. Wound cultures were positive for Stafilococcus aureus. After a 5 day antibiotic treatment course with piperaciline+ tazobactam 4 gr e.v. $6 / 6 \mathrm{~h}$, the patient was discharged from the hospital. One month later, a $5 \mathrm{~cm}$ long portion of transobturator monofilament polypropylene sling (Mentor ObTape) was extrused through the vagina, upon minimal pressure.

\section{Discussion}

Transobturator suburethral tapes are increasingly used for the treatment of female stress urinary incontinence with minimal complications. Even though the transobturator approach reduces potential bladder, bowel, and vascular injury when properly performed, potential serious complications can occur even in minimally invasive sling techniques. Patients undergoing transobturator slings with signs of inflammation of the thigh and that do not respond to initial antibiotic therapy, abscess formation should always be investigated and ruled out. Actually the use of mesh $>75 \mu \mathrm{m}$ is recommended to allow macrophages to invade the graft material and enable ingrowth with less infectious complications. Nowadays the use of Mentor ObTape is abandoned in our unit because of high rates of extrusion and mesh rejection.

\section{References}

1. Delorme E (2001) Transobturator urethral suspension: miniinvasive procedure in the treatment of stress urinary incontinence in women. Prog Urol 11(6):1306-1313

2. Babalola EO, Famuyide AO, McGuire LJ, Gebhart JB, Klingele CJ (2006) Vaginal erosion, sinus formation, and ischiorectal abscess following transobturator tape: ObTape implantation. Int Urogynecol J Pel 17(4):418-421

3. Goldman H (2006) Large thigh abscess after placement of synthetic transobturator sling. Int Urogynecol J Pel 17(3):295-296 